NBER WORKING PAPER SERIES

\title{
DEMOGRAPHIC CHANGE, RELATIVE FACTOR PRICES, INTERNATIONAL CAPITAL FLOWS, AND THEIR DIFFERENTIAL EFFECTS ON THE WELFARE OF GENERATIONS
}

\author{
Alexander Ludwig \\ Dirk Krueger \\ Axel H. Boersch-Supan \\ Working Paper 13185 \\ http://www.nber.org/papers/w13185 \\ NATIONAL BUREAU OF ECONOMIC RESEARCH \\ 1050 Massachusetts Avenue \\ Cambridge, MA 02138 \\ June 2007
}

We thank conference participants and researchers at several places for their helpful comments, in particular Martin Floden, Ayse Imrohoroglu, Jim Poterba and Sandra Svaljek. This research was supported by the U.S. Social Security Administration through grant \#10-P-98363-1-03 to the National Bureau of Economic Research as part of the SSA Retirement Research Consortium and by the sponsors of MEA, the Land of Baden-Württemberg, the German Association of Insurers (GDV) and the German Science Foundation (DFG). The findings and conclusions expressed are solely those of the author(s) and do not represent the views of SSA, any agency of the Federal Government, the NBER, or any other sponsor. This paper was prepared for the 2006 NBER Conference on Social Security research from the Retirement Research Center in Woodstock, VT. The views expressed herein are those of the author(s) and do not necessarily reflect the views of the National Bureau of Economic Research.

(C) 2007 by Alexander Ludwig, Dirk Krueger, and Axel H. Boersch-Supan. All rights reserved. Short sections of text, not to exceed two paragraphs, may be quoted without explicit permission provided that full credit, including $(\mathcal{O}$ notice, is given to the source. 
Demographic Change, Relative Factor Prices, International Capital Flows, and Their Differential Effects on the Welfare of Generations

Alexander Ludwig, Dirk Krueger, and Axel H. Boersch-Supan

NBER Working Paper No. 13185

June 2007

JEL No. C68,D33,E17,E25

\section{ABSTRACT}

Demographic change has differential impacts on the welfare of current and future generations. In a simple closed economy, aging -- a relative scarcity of young workers -- increases wages, increasing the welfare of the young. At the same time, population aging will reduce rates of return to capital, thereby reducing the welfare of asset holders who are usually older than the population average. In a global world with pension systems, however, these effects are less straightforward, since international capital flows dampen the factor price changes. Moreover, pay-as-you-go pension systems financed by payroll taxes create a wedge between net and gross wages, and their intergenerational redistribution has important additional effects on the welfare of generations. To quantify these effects, we develop a large-scale multi-country overlapping generations model with uninsurable labor productivity and mortality risk. Due to the predicted relative abundance of the factor capital, the rate of return falls between 2005 and 2050 by roughly 90 basis points. Our simulations indicate that capital flows from rapidly ageing regions to the rest of the world will initially be substantial, but that trends are reversed when households de-cumulate savings. In terms of welfare, our model suggests that young individuals with little assets and currently low labor productivity indeed gain from higher wages associated with population aging. Older, asset-rich households tend to loose because of the predicted decline in real returns to capital.

Alexander Ludwig

Mannheim Research Institute for the

Economics of Aging

Universität Mannheim

Building L13, 17

D-68131 Mannheim

GERMANY

alexander.ludwig@mea.uni-mannheim.de

Dirk Krueger

Associate Professor

Department of Economics

University of Pennsylvania

3718 Locust Walk

Philadelphia, PA 19104

and NBER

dkrueger@econ.upenn.edu
Axel H. Boersch-Supan

Mannheim Research Institute for the

Economics of Aging

University of Mannheim

Building L13, 17

D-68131 Mannheim, GERMANY

and NBER

axel@boersch-supan.de 


\title{
Demographic Change, Relative Factor Prices, International Capital Flows, and Their Differential Effects on the Welfare of Generations ${ }^{1}$
}

\author{
Alexander Ludwig ${ }^{*}$, Dirk Krüger, ${ }^{*, * * * *}$, and Axel Börsch-Supan ${ }^{* * * *}$ \\ *Mannheim Research Institute for the Economics of Aging (MEA), Universität Mannheim, \\ Germany \\ **National Bureau of Economic Research (NBER), Cambridge, Mass., USA \\ *** Department of Economics, Goethe Universität Frankfurt, Germany
}

Demographic change has differential impacts on the welfare of current and future generations. In a simple closed economy, aging - a relative scarcity of young workers - increases wages, increasing the welfare of the young. At the same time, population aging will reduce rates of return to capital, thereby reducing the welfare of asset holders who are usually older than the population average.

In a global world with pension systems, however, these effects are less straightforward, since international capital flows dampen the factor price changes. Moreover, pay-as-you-go pension systems financed by payroll taxes create a wedge between net and gross wages, and their intergenerational redistribution has important additional effects on the welfare of generations.

To quantify these effects, we develop a large-scale multi-country overlapping generations model with uninsurable labor productivity and mortality risk. Due to the predicted relative abundance of the factor capital, the rate of return falls between 2005 and 2050 by roughly 90 basis points. Our simulations indicate that capital flows from rapidly ageing regions to the rest of the world will initially be substantial, but that trends are reversed when households de-cumulate savings. In terms of welfare, our model suggests that young individuals with little assets and currently low labor productivity indeed gain from higher wages associated with population aging. Older, assetrich households tend to loose because of the predicted decline in real returns to capital.

JEL Classification: E17, E25, D33, C68

Keywords: Population Aging, Relative Factor Prices, International Capital Flows, Distribution of Welfare

\footnotetext{
${ }^{1}$ We thank conference participants and researchers at several places for their helpful comments, in particular Martin Floden, Ayse Imrohoroglu, Jim Poterba and Sandra Svaljek. This research was supported by the U.S. Social Security Administration through grant \#10-P-98363-1-03 to the National Bureau of Economic Research as part of the SSA Retirement Research Consortium and by the sponsors of MEA, the Land of Baden-Württemberg, the German Association of Insurers (GDV) and the German Science Foundation (DFG). The findings and conclusions expressed are solely those of the author(s) and do not represent the views of SSA, any agency of the Federal Government, the NBER, or any other sponsor. This paper was prepared for the 2006 NBER Conference on Social Security research from the Retirement Research Center in Woodstock, VT.
} 


\section{Introduction}

In all major industrialized countries the population is aging, over time reducing the fraction of the population in working age. This process is driven by falling mortality rates followed by a decline in birth rates. This reduces population growth rates; in some countries, population will even decline. While demographic change occurs in all countries in the world, extent and timing differ substantially. Europe and some Asian countries have almost passed the closing stages of the demographic transition process while Latin America and Africa are only at the beginning (Bloom and Williamson, 1998; United Nations, 2002).

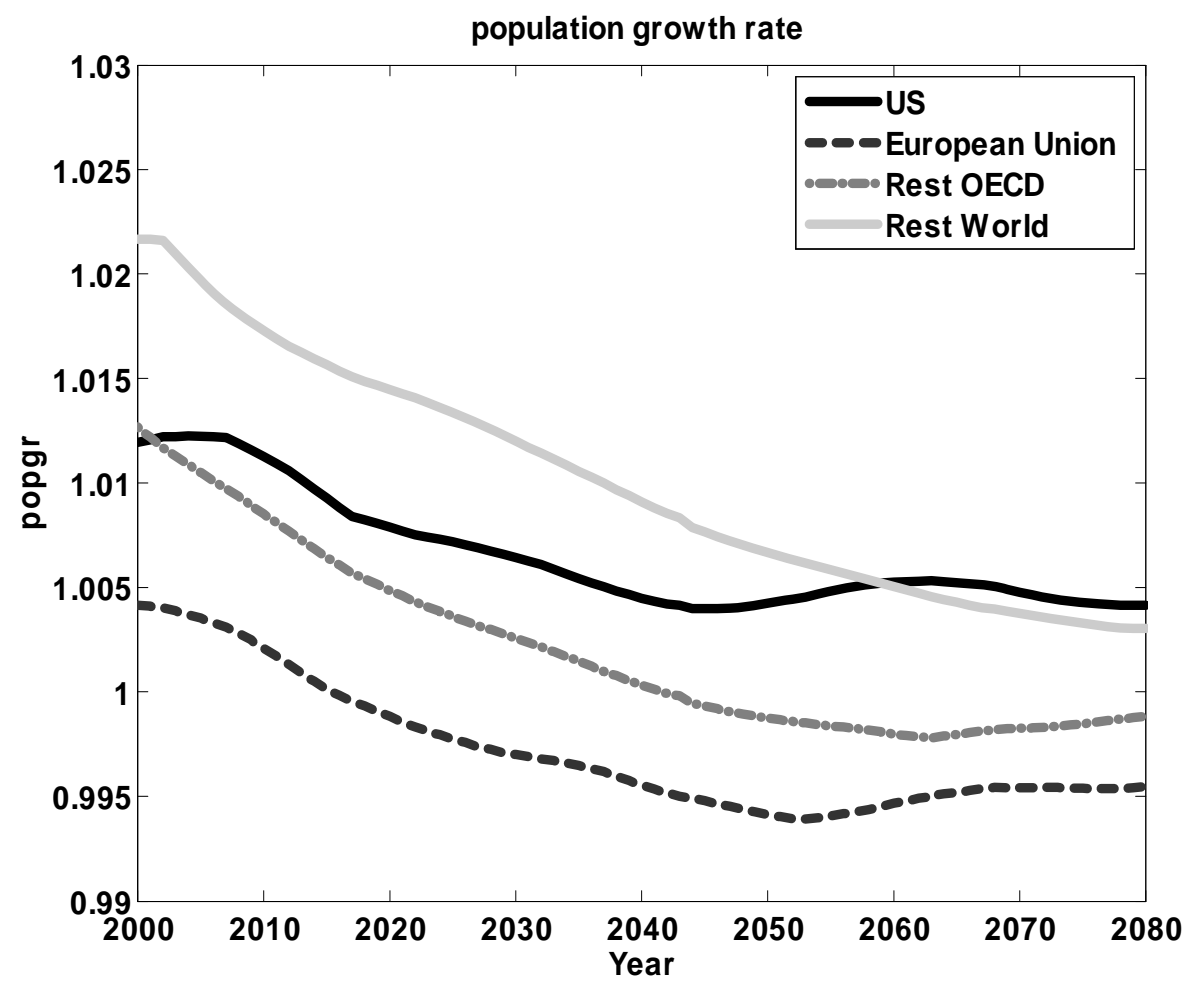

Figure 1: Evolution of the Population Growth Rate in 4 Regions

Figure 1, based on UN population projections (United Nations, 2002), illustrates the differential impact of demographic change on population growth rates for the period 2000-2080. They are defined as the growth rate of the adult population, aggregated into four mutually exclusive regions of the world: the U.S., the European Union (EU), the rest of the OECD (ROECD) and the rest of the world (ROW).

Population growth rates are predicted to decline in all regions, but to remain positive in the U.S. 
and in the ROW region throughout the 21 st century. In contrast, they will become negative in the EU by about 2016 and in the ROECD by about 2042, such that their populations start shrinking, while the populations of the other two world regions continue to grow.

These striking differences in demographic change will change the global balance; induce differential factor price changes and international flows of labor, capital and products. All this will affect the welfare of the people living in these regions. This is the topic of this paper. As we will see, welfare is affected differentially not only across regions but also across generations.

Figure 2 shows the impact of demographic change on working-age population ratios - the ratio of the working-age population (of age 20-64) to the total adult population (of age 20-95). This indicator, which will turn out to be crucial in our analysis, illustrates that the EU is the oldest, whereas the ROW is the youngest region in terms of the relative size of the working-age population. The United States and the rest of the OECD region initially have the same level of working-age population ratios, but the dynamics of demographic change differ substantially in the U.S. relative to the other regions. While working-age population ratios decrease across all regions, the speed of this decrease significantly slows down for the U.S. in about 2030.

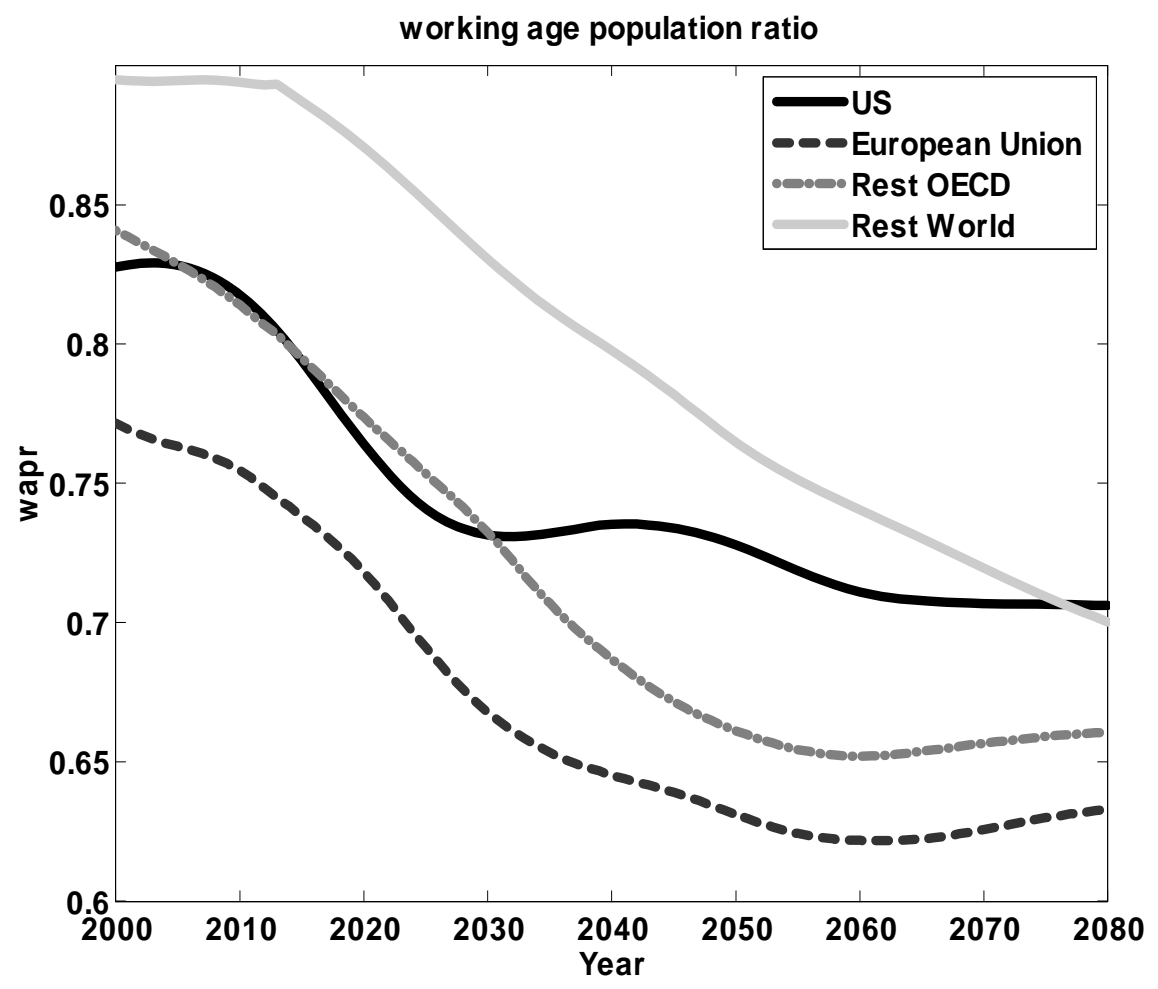

Figure 2: Evolution of Working Age to Population Ratios in 4 Regions 
The paper continues a line of research by Börsch-Supan (1996), Börsch-Supan, Ludwig and Winter (2002), Börsch-Supan, Ludwig and Winter (2006) and, especially, Krüger and Ludwig (2006) that aim to quantify the effects of demographic change on macroeconomic developments and welfare. What are the effects of these long-run developments on relative factor prices and welfare? What are the additional effects of ongoing pension reforms that convert the pay-as-yougo (PAYGO) pension systems into multi-pillar systems with potentially large capital stocks?

The basic effects are intuitive: First, the changes in the population structure will alter aggregate labor supply and aggregate savings. This will change factor prices for labor and capital. Since labor will become scarcer, relative to capital, real wages will increase and real rates of return to capital will decrease. Second, if countries reform their PAYG pension systems, the additional supply of capital increases the downward pressure on the rates of return. This will have differential effects on the welfare of generations. The young may gain through higher wages, while the old may loose due to lower capital returns.

While these basic mechanisms are intuitive, their quantification is difficult, especially in an international context. Quantification, however, is important in order to understand the implications for social security reform. If capital returns decline very little, welfare implications will also be small. If returns decline catastrophically, like suggested by some proponents of the so called "asset meltdown" hypothesis, pension reforms, that substitute parts of the PAYGO social security system by prefunded accounts, may create large welfare losses for future pensioners.

This paper feeds the demographic projections by the United Nations into a computable overlapping generations' model of the type pioneered by Auerbach and Kotlikoff (1987). We extend the model to a multi-country version as in Börsch-Supan, Ludwig and Winter (2006) and enrich the model by uninsurable idiosyncratic uncertainty, as in Imrohoroglu, Imrohoroglu and Joines (1995), Imrohoroglu, Imrohoroglu and Joines (1999), Conesa and Krueger (1999) and Krüger and Ludwig (2006) plus risk insured by the social security system as modeled by Nataraj and Shoven (2003).

Both extensions are indispensable for the welfare questions we want to address. First, employing a multi-country view is essential as capital markets are global and populations age differentially; for instance, the countries which supply capital to the U.S. age faster than the U.S. In our model capital can freely flow between different regions in the OECD (the U.S., the EU and the rest of the OECD). These capital flows may mitigate the decline in rates of return and the increase in 
real wages from the perspective of fast aging economies such as the European countries.

Second, uninsurable idiosyncratic uncertainty will endogenously give rise to some individuals deriving most of their income from returns to capital, while the income of others is mainly composed of labor income. Abstracting from this heterogeneity does not allow a meaningful analysis of the distributional consequences of aging-induced changes in factor prices. This model feature also adds a precautionary savings motive to the standard life-cycle savings motive of households, which makes life cycle savings profiles generated by the model more realistic.

We find that the rate of return to capital decreases by roughly 80 to 90 basis points if capital is allowed to freely flow across regions. Our simulations indicate that capital flows from rapidly ageing regions to the rest of the world will initially be substantial, but that trends are reversed when households decumulate savings. However, due to the high correlation of long-run demographic developments among OECD countries in terms of trends in the working age population ratio, compare Figure 2, these capital flows do not affect much the long-run decrease of the rate of return. The latter does not change much whether we assume the U.S. (or Europe) to be closed or open economies.

In order to evaluate the welfare consequences of the demographic transition we ask the following question: suppose a household economically born in 2005 would live through the economic transition with changing factor prices induced by the demographic change (but keeping its own survival probabilities constant at their 2005 values), how would its welfare have changed, relative to a situation without a demographic transition? We find that for young households with little assets the increase in wages dominates the decline in rates of return. Abstracting from social security and its reform, newborns in 2005 gain in the order of $0.6-0.9 \%$ in terms of lifetime consumption. Older, asset-rich individuals, on the other hand, tend to lose because of the decline in interest rates. If the demographic transition, in addition, makes a reform of the social security system necessary, then falling benefits or increasing taxes reduce the welfare gains for newborn individuals. An increase in the retirement age to 70 , on the other hand, mitigates some of these negative consequences.

Our paper borrows model elements from, and contributes to, three strands of the literature. Starting with Auerbach and Kotlikoff (1987) a vast number of papers has used large-scale OLG models to analyze the transition path of an economy induced by a policy reform. Examples include social security reform (see e.g. Conesa and Krueger, 1999) and fundamental tax reform 
(see e.g. Altig, Auerback, Kotlikoff, Smetters and Walliser, 2001, Conesa and Krueger, 2005).

A second strand of the literature (often using the general methodology of the first strand) has focused on the economic consequences of population aging in closed economies, often paying special attention to the adjustments required in the social security system due to demographic shifts. Important examples include Huang, İmrohoroğlu and Sargent (1997), De Nardi, İmrohoroğlu and Sargent (1999), and, with respect to asset prices, Abel (2003).

The contributions discussed so far assume that the economy under investigation is closed to international capital flows. However, as the population ages at different pace in various regions of the world one would expect capital to flow across these regions. The third strand of the literature our paper touches upon therefore is the large body of work in international macroeconomics studying the direction, size, cause and consequences of international capital flows and current account dynamics, reviewed comprehensively in Obstfeld and Rogoff (1995).

Our paper is most closely related to work that combines these three strands of the literature, by using the methodology of large scale OLG models to study the consequences of demographic change in open economies. The work by Attanasio, Kitao and Violante (2006a, 2006b) construct a two region (the North and the South) OLG model to study the allocative and welfare consequences of different social security reforms in an open economy. Compared to their model, we include endogenous labor supply and idiosyncratic income shocks.

Similar to our own work, Fehr, Jokisch and Kotlikoff (2005) investigate the impact of population aging on the viability of the social security system and its reform. Building on earlier work by Brooks (2003) who employs a simple four period OLG model, Henriksen (2002), Feroli (2003) and Domeij and Floden (2005) use large scale simulation models similar to Börsch-Supan, Ludwig and Winter (2006) to explain historical capital flow data with changes in demographics, rather than, as we do, to study the welfare and distributional implications of future changes in demographics. Relative to this literature, we see the contribution of our paper in evaluating the welfare consequences of the demographic transition per se and not just the alternative social security reform scenarios, as well as in the analysis of the distributional consequences of changing factor prices due to population aging.

The paper is organized as follows. Section 2 presents a simple two-period OLG model to illustrate the relationship between demographic change, per capita consumption and welfare. 
Section 3 contains the description of our large scale quantitative simulation model and section 4 presents our main results. Finally, section 5 concludes.

\section{A Simple Model}

Key for understanding the results in section 4 is to notice that per capita consumption and individual welfare are entirely different concepts in OLG economies. Per capita consumption and output are cross-sectional measures referring to all households currently alive whereas welfare is a cohort based measure. Relevant for utility over the life-cycle are wages, interest rates and how consumption and leisure are weighted at different ages. Due to discounting, utility from future consumption is lower than from current consumption, giving more weight to consumption and leisure at young ages.

As societies are aging, labor becomes relatively scarce and capital relatively abundant which leads to increases of wages and decreases in rates of return. This implies that the consumption profile is tilted over the life-cycle such that the young consume relatively more than the old. In per capita consumption, allocations are weighted with cohort sizes. Hence, as a consequence of demographic change, the size of those who consume more - the young - decreases whereas the size of those who consume less - the old - increases. If this compositional effect is stronger than the direct effect of a decrease in size of the overall population, per capita consumption decreases.

However, from a life-cycle perspective, consumption when being young is relatively higher and consumption when being old is relatively lower. If the higher consumption at young ages has a higher utility weight than the lower consumption at older ages, then individual welfare increases. This leads to a result which is counterintuitive at first sight: per capita consumption and welfare may move into different directions. Demographic change leads to a reduction of per capita consumption, yet, at the same time, it also leads to an increase of the newborns' life-time welfare, at least in the absence of social security.

We now illustrate these insights using a simplified version of the Diamond (1965) model. Krüger and Ludwig (2006) develop an open economy version of the model with social security in order to illustrate the various interactions between demographic change, social security and international capital flows. Here, we do not address all these issues and focus on a closed 
economy without social security. We also abstract from technological progress. ${ }^{2}$

\subsection{Households}

There are $N_{t}$ young households who live for two periods and have preferences over consumption $c_{t}^{y}, c_{t+1}^{o}$ representable by the utility function

$$
\log \left(c_{t}^{y}\right)+\beta \log \left(c_{t+1}^{o}\right)
$$

In the first period of their lives households work for a wage $w_{t}$ and in the second period they retire. Since we ignore social security the budget constraints read as

$$
\begin{aligned}
c_{t}^{y}+s_{t} & =w_{t} \\
c_{t+1}^{o} & =\left(1+r_{t+1}\right) s_{t}
\end{aligned}
$$

where $r_{t+1}$ is the real interest rate between period $t$ and $t+1$.

\subsection{Firms}

The production function is given by

$$
Y_{t}=K_{t}^{\alpha}\left(N_{t}\right)^{1-\alpha}
$$

where $Y_{t}$ is output and $K_{t}$ is the aggregate capital stock.

The production technology is operated by a representative firm that behaves competitively in product and factor markets. Assuming that capital depreciates fully after its use in production, profit maximization of firms implies that

\footnotetext{
${ }^{2}$ Certainly our results on per capita consumption and welfare also hold in an open economy model where relative prices are driven by the impact of the countries' relative sizes, see Krüger and Ludwig (2006) for more details.
} 


$$
\begin{aligned}
1+r_{t} & =\alpha k_{t}^{\alpha-1} \\
w_{t} & =(1-\alpha) k_{t}^{\alpha},
\end{aligned}
$$

where

$$
k_{t}=\frac{K_{t}}{N_{t}}
$$

is the capital intensity.

\subsection{Aggregation}

Market clearing requires that

$$
K_{t+1}=N_{t} s_{t}
$$

from which we also have that

$$
k_{t+1}=\frac{s_{t}}{\gamma_{t+1}^{N}}
$$

where $\gamma_{t}^{N}$ is the gross growth rate of the young cohort between periods $t-1$ and $t$. It also measures the working age to population ratio (the higher is $\gamma_{t}^{N}$, the higher is that ratio), which allows us to map the predictions of this model to the data plotted in figure $2 .^{3}$

\footnotetext{
${ }^{3}$ The population at time $t$ is given by $P_{t}=N_{t}+N_{t-1}$ and the working age to population ratio is given by

$$
\frac{N_{t}}{N_{t}+N_{t-1}}
$$
}

which we can rewrite as 
Equilibrium in this model can be characterized analytically. To do so we first solve the household problem and then aggregate across households.

Optimal savings of the young are given as

$$
s_{t}=\frac{\beta}{1+\beta} w_{t} .
$$

Substituting out for wages from above gives

$$
\mathrm{s}_{\mathrm{t}}=\frac{\beta(1-\alpha)}{1+\beta} \mathrm{k}_{\mathrm{t}}^{\alpha} .
$$

From the capital market clearing condition we now get that

$$
\mathrm{k}_{\mathrm{t}+1}=\frac{(1-\alpha) \beta}{(1+\beta) \gamma_{\mathrm{t}+1}^{\mathrm{N}}} \mathrm{k}_{\mathrm{t}}^{\alpha} .
$$

In the steady state we have that $\gamma_{t}^{N}=\gamma^{N}$ and $k_{t+1}=k_{t}=k^{*}$ where $k^{*}$ is the steady state capital stock given by

$$
k^{\star}=\left(\frac{\phi}{\gamma^{N}}\right)^{\frac{1}{1-\alpha}}
$$

where $\phi=\frac{(1-\alpha) \beta}{1+\beta}$.

$$
\frac{1}{1+\frac{1}{\gamma_{t}^{N}}}
$$

Thus $\gamma_{t}^{N}$ is a measure both of the population growth rate as well as the working age to population ratio. 


\subsection{Analysis}

Steady state consumption when young and old can now be written as

$$
\begin{aligned}
& \mathrm{c}^{\mathrm{y}}=\frac{1-\alpha}{1+\beta} \mathrm{k}^{\alpha} \\
& \mathrm{c}^{\mathrm{o}}=\beta \alpha \mathrm{k}^{\alpha-1} \mathrm{c}^{\mathrm{y}} .
\end{aligned}
$$

From the utility function we can then derive that

$$
\begin{aligned}
\mathrm{u} & =\ln \left(\mathrm{c}^{\mathrm{y}}\right)+\beta \ln \left(\mathrm{c}^{\mathrm{o}}\right) \\
& =\Psi-\frac{[\alpha(1+\beta)-\beta(1-\alpha)]}{1-\alpha} \ln \gamma^{\mathrm{N}},
\end{aligned}
$$

where $\psi$ is some constant term that is independent of the exogenous variable $\gamma^{N}$.

It now immediately follows that utility decreases in $\gamma^{N}$ (or increases in $\ln k$ ) if and only if

$$
\begin{aligned}
& \alpha(1+\beta)-\beta(1-\alpha)>0 \\
\Leftrightarrow & \alpha>\frac{(1-\alpha) \beta}{1+\beta} .
\end{aligned}
$$

Notice that this is just the same condition as requiring the economy to be dynamically efficient because the golden rule capital stock maximizing per capita consumption is given by

$$
\mathrm{k}^{* *}=\left(\frac{\alpha}{\gamma^{\mathrm{N}}}\right)^{\frac{1}{1-\alpha}}
$$

that is, if $\alpha>\frac{(1-\alpha) \beta}{1+\beta}$ then $k^{* *}>k^{*}$.

We therefore have the result that in a dynamically efficient economy, utility is increased as the population growth rate is reduced. But from this we cannot conclude that decreases of the population growth rate lead to increases in per capita consumption because a decrease of $\gamma^{N}$ leads to an increase of $k^{* *}$ and $k^{*}$. 
To clarify this we now derive analytic expressions for per capita output and consumption. Let $P$ be total population. Notice that we can write steady state per capita output as

$$
\frac{Y}{P}=\frac{k^{\alpha} N}{P}=\frac{k^{\alpha} \gamma^{N}}{1+\gamma^{N}}
$$

Using the equilibrium for the steady state capital intensity, we can rewrite this expression as

$$
\frac{\mathrm{Y}}{\mathrm{P}}=\phi^{\frac{\alpha}{1-\alpha}} \gamma^{\mathrm{N}-\frac{\alpha}{1-\alpha}} \frac{\gamma^{\mathrm{N}}}{1+\gamma^{\mathrm{N}}}
$$

We therefore have that

$$
\frac{\partial \frac{Y}{P}}{\partial \gamma^{N}}=\phi^{\frac{\alpha}{1-\alpha}} \gamma^{N-\frac{\alpha}{1-\alpha}} \frac{1}{1+\gamma^{N}}\left[\frac{1}{1+\gamma^{N}}-\frac{\alpha}{1-\alpha}\right]
$$

That is, per capita output increases in $\gamma^{N}$ if and only if

$$
\alpha<\frac{1}{2+\gamma^{\mathrm{N}}},
$$

which becomes less strong as $\gamma^{N}$ is smaller (that is in economies with a shrinking population).

As for per capita consumption we have that

$$
\begin{aligned}
\frac{C}{P} & =\frac{c^{y} N^{y}+c^{o} N^{o}}{N^{y}+N^{0}} \\
& =\frac{c^{y} N^{o}\left(\gamma^{N}+\beta \alpha k^{\alpha-1}\right)}{N^{0}\left(\gamma^{N}+1\right)} \\
& =\left(1+\alpha \beta \phi^{-1}\right) \frac{1-\alpha}{1+\beta} \phi^{\frac{\alpha}{1-\alpha}} \gamma^{N^{-\frac{\alpha}{1-\alpha}}} \frac{\gamma^{N}}{1+\gamma^{N}},
\end{aligned}
$$

which, apart from the constant, has the same form as the equation for per capita output. Therefore, the same condition as before applies.

We can summarize these findings as follows: Starting from an initial steady state, then if $\gamma^{N}$ falls we have - in the new steady state that the economy converges to - that (i) welfare of newborns is 
unambiguously higher if the economy is dynamically efficient, that is, if $\alpha>\frac{(1-\alpha) \beta}{1+\beta}$ and (ii) per capita output and consumption are lower than in the initial steady state if $\alpha<\frac{1}{2+\gamma^{N}}$.

This intuition derived from our simple model illustrates that per capita consumption and welfare may move into different directions.

\section{The Quantitative Model}

The quantitative model we use to evaluate the consequences of demographic changes for international capital flows, returns to capital and wages, as well as the welfare consequences emanating from these changes is the same as in Krüger and Ludwig (2006). We focus on the industrialized world decomposed into three regions: the United States (U.S.), the European Union (EU) and the rest of the OECD (ROECD).

We can think of our simulation model as an engine for the following thought experiment: We allow country-specific survival, fertility and migration rates to change over time, inducing a demographic transition. Induced by the transition of the population structure is a transition path of the economies of the model, both in terms of aggregate variables as well as cross-sectional distributions of wealth and welfare. Summary measures of these changes will provide us with answers as to how the changes in the demographic structure of the economy, by changing returns to capital and wages, impact the distribution of welfare. Eventually, given by the assumption of a stable demography in the very far future, the economies will reach a steady state which permits the computation of the transition paths.

Specifically, we start computations in year 1950 assuming an artificial initial steady state. We then use data for a calibration period, 1950-2004, to determine several structural model parameters. We then compute the model equilibrium from 1950 to 2050, the transition path of interest, and further onwards until the new steady state is assumed in 2300 , far into the future. ${ }^{4}$

\footnotetext{
${ }^{4}$ The steady state year of 2300 is chosen far into the future in order to avoid any contamination of the transition path between 2005 and 2050.
} 


\subsection{Demographics}

The demographic evolution in our model is taken as exogenous. ${ }^{5}$ It is the main driving force of our model in addition to the design of the social security system, see section 3.4. Households start their economic life at age 20, retire at age 65 and live at most until age 95 . Since we do not model childhood of a household explicitly, we denote its twentieth year of life by $j=0$, its retirement age by $j r=45$ and the terminal age of life by $\mathrm{J}=75$. Households face an idiosyncratic, time- and country-dependent (conditional) probability to survive from age $j$ to age $j+1$, which we denote by $s_{t, j, i}$.

For each country $i$ we have data or forecasts for populations of model age $j \in\{0, \ldots, 75\}$ in years $1950, \ldots, 2300$. From now on we denote year 1950 as our base year $t=0$ and year 2300 as the final period $T$ and the demographic data for periods $t \in\{0, \ldots, T\}$ by $N_{t, j, i}$. For simplicity, we assume that all migration takes place at or before age $j=0$ in the model (age 20 in the data), so that we can treat migrants and individuals born inside the country of interest symmetrically.

\subsection{Technology}

In each country the single consumption good is being produced according to a standard neoclassical production function

$$
Y_{t, i}=Z_{i} K_{t, i}^{\alpha}\left(A_{t} L_{t, i}\right)^{1-\alpha}
$$

Where $Y_{t, j}$ is output in country $i$ at date $t, K_{t, j}$ and $L_{t, j}$ are capital and labor inputs and $A_{t}$ is total labor productivity, growing at a constant country independent rate $g$. The scaling parameters $Z_{i}$ control relative total factor productivities across countries, whereas the parameter $\alpha$ measures the capital share and is assumed to be constant over time and across countries. In each country capital used in production depreciates at a common rate $\delta$. Since production takes place with a constantreturns to scale production function and since we assume perfect competition, the number of firms is indeterminate in equilibrium and, without loss of generality, we assume that a single representative firm operates within each country.

\footnotetext{
${ }^{5}$ While the UN demographic forecasts include a projection of future fertility rates, mortality rates, and migration flows, these projections are not modified by our model output.
} 


\subsection{Endowments and Preferences}

Households value consumption and leisure over the life cycle according to a standard timeseparable utility function

$$
E\left\{\sum_{j=0}^{J} \beta^{j} u\left(c_{j}, 1-l_{j}\right)\right\}
$$

where $\beta$ is the raw time discount factor and expectations are taken over idiosyncratic mortality shocks and stochastic labor productivity. In particular, the expectations operator $E$ encompasses the survival probabilities $s_{t, j, i}$.

Households are heterogeneous with respect to age, a deterministic earnings potential and stochastic labor productivity. These sources of heterogeneity affect a household's labor productivity which is given by

$$
\theta_{k} \varepsilon_{j} \eta
$$

First, households' labor productivity differs according to their age: $\varepsilon_{j}$ denotes average agespecific productivity of cohort $j$. Second, each household belongs to a particular group $k \in\{1, \ldots, K\}$ that shares the same average productivity $\theta_{k}$. Differences in groups stand in for differences in education or ability, characteristics that are fixed at entry into the labor market and affect a group's relative wage. We introduce these differences in order to generate part of the cross-sectional income and thus wealth dispersion that does not come from our last source of heterogeneity, idiosyncratic productivity shocks. Lastly, a household's labor productivity is affected by an idiosyncratic shock, $\eta \in\{1, \ldots, E\}$, that follows a time-invariant Markov chain with transition probabilities

$$
\theta_{k} \varepsilon_{j} \eta
$$

We denote by $\Pi$ the unique invariant distribution associated with $\pi$. 


\subsection{Government Policies}

Key government policy in, and the second exogenous driving force of, our model is pension policy. The main ingredient are country-specific pay-as-you-go (PAYGO) public pension systems whose taxes and benefits will adjust to the demographic changes in each country. On the revenue side, households pay a flat payroll tax rate, $\tau_{t, i}$, on their labor earnings. Retired households receive benefits, $b_{t, k, i}$, that are assumed to depend on the household type, $\theta_{k}$, but are independent of the history of idiosyncratic productivity shocks. Social security benefits are therefore given by

$$
b_{t, k, i}=\rho_{t, i} \theta_{k}\left(1-\tau_{t, i}\right) w_{t, i},
$$

where $\rho_{t, i}$ is the pension system's net replacement rate.

We assume that the budget of the pension system is balanced at all times such that taxes and benefits are related by

$$
\tau_{t, i} w_{t, i} L_{t, i}=\sum_{k} b_{t, k, i} \sum_{j \geq j r} N_{t, j, k, i},
$$

where $N_{t, j, k, i}$ denotes the population in country $i$ at time $t$ of age $j$ and type $k$.

In order to shed light on the interaction between the implications of demographic change and the type of social security system, we apply four different scenarios for the future evolution of the social security system:

- Scenario 1 models a defined contribution PAYGO system in which taxes are held constant and replacement rates adjust according to the demographic change.

- Scenario 2 models a defined benefit PAYGO system in which replacement rates are held constant and taxes adjust according to the demographic change.

- A third scenario models an increase in the retirement age and, in addition, adjusts benefits, if needed, to assure budget balance.

- Finally, as a benchmark, our fourth scenario has no PAYGO system altogether such that all 
old-age provision is done via private savings modeled by the life-cycle saving and consumption decisions of the households.

In addition to its role as governor of the social security system, the government also distributes accidental bequests left by those households who die before age $J$. It collects their assets and redistributes them in a lump-sum fashion among the remaining citizens of the country.

\subsection{Market Structure}

In each period there are spot markets for the consumption good, for labor and for capital services. While the labor market is a national market where labor demand and labor supply are equalized country by country, the markets for the consumption good and capital services are international where goods and capital flow freely, and without any transaction costs, between countries. The supply of capital for production stems from households in all countries who purchase these assets in order to save for retirement and to smooth idiosyncratic productivity shocks. As sensitivity analysis, we explore how countries would be affected by their demographic changes if they were closed economies where capital stocks and accumulated assets coincide by definition.

\subsection{Equilibrium}

A competitive equilibrium in this economy is defined by sequences of individual decision functions, sequences of production plans for firms, sequences of policies by the government, prices, transfers and cross-sectional measures such that (i) households and firms behave optimally, (ii) the government budget constraint holds, and (iii) aggregation conditions hold and (iv) markets clear. A stationary equilibrium is a competitive equilibrium in which all individual functions are constant over time and all aggregate variables grow at a constant rate. A formal definition of equilibrium is given in Krüger and Ludwig (2006).

\subsection{Calibration}

Calibration of the model is based on the minimum distance method developed in Ludwig (2005) extensively in Krüger and Ludwig (2006). Tables I and II summarize the information on the values of technology and preference parameters, respectively. Notice that some of these parameters are restricted to be identical across regions while others are allowed to differ. In particular, total factor productivities, $Z_{i}$, are scaled such as to match labor productivities and consumption share parameters, $\omega_{i}$, are determined such as to match hours worked in the three 
regions of our model.

Table I: Technology Parameters

\begin{tabular}{llll}
\hline Parameter & U.S. & EU & ROECD \\
\hline Capital Share $\alpha$ & & 0.33 & \\
Growth Rate of Technology $g$ & & 0.018 & \\
Depreciation Rate $\delta$ & 1.0 & 0.04 & 0.65 \\
Total Factor Productivity $Z_{i}$ & & 0.88 & \\
\hline \hline
\end{tabular}

Table II: Preference Parameters

$\begin{array}{llll}\text { Parameter } & \text { U.S. } & \text { EU } & \text { ROECD }\end{array}$

Coefficient of RRA $\sigma$

Time Discount Factor $\beta$

Consumption Share Parameter $\omega_{i}$
0.463
1.0

0.9378

0.446

0.442

Data for calibrating the social security system are taken from various sources. For the U.S., we calculate social security contribution rates from NIPA data taken from the BEA Table 3.6. For the other world regions, we proxy the time path of social security contribution rates by using time path information on total labor costs taken from the BLS and scale these data by the social security contribution rates reported by the OECD. Using these contribution rates and the demographic data, we back out replacement rates by the PAYGO budget constraint. 


\subsection{Solution Method}

For given structural model parameters we solve for the equilibrium of the model in separate outer and inner loop iterations. Throughout we take as length of the period one year. Outer loop iterations search for equilibrium interest rates, contribution rates and accidental bequests using a modification of the familiar Gauss-Seidel algorithm (see Ludwig, 2006). Recursive methods are used to solve the household model in inner loop iterations which are described in detail in Krüger and Ludwig (2006).

\section{Results}

In order to isolate the direct effects of demographic changes on returns to capital, international capital flows, and the distribution of wealth and welfare we first abstract from social security in our analyses of sections 4.1 through 4.3. In section 4.4 we quantify the additional effects that are implied by the adjustments of social security parameters to demographic change.

One element that distinguishes our model from the earlier work in Börsch-Supan, Ludwig and Winter (2006) is idiosyncratic risk. This enables us to characterize the distributional consequences of demographic change in a more realistic setting. In section 4.5 we address its implications for the general equilibrium rates of return and wages as well as for welfare. Throughout we assume that capital flows freely between regions in the OECD.

\subsection{Dynamics of Aggregate Statistics}

In figure 3 we display the evolution of the real return to capital from 2000 to 2080 . In the same figure we plot, as a summary measure of the age structure of the population, the fraction of the world adult population with age above 65 (by assumption these individuals are retired in our model); this statistic is one minus the working age to population ratio. We observe that the rate of world-wide return to capital is predicted to fall by almost 1 percentage point in the next 60 years and then to settle down at that lower level.

Pre-tax wages are related to the interest rate by

$$
w_{t, i}=(1-\alpha) Z_{i} A_{t}\left(\frac{\alpha Z_{i}}{r_{t}+\delta}\right)^{\frac{\alpha}{1-\alpha}}
$$


and thus de-trended (by productivity growth) real wages follow exactly the inverse path of interest rates, documented in figure irbench. These de-trended wages are predicted to increase by roughly $4 \%$ between 2000 and 2050 in all regions in our model.

In figure 4 we plot the evolution of de-trended output per capita in the three regions, normalized to 1 in the year 2000. Notice that per capita here refers to the adult population aged 20 to 95 . We observe substantial declines of 7 to $13 \%$ in the three regions. The decline is least pronounced in the U.S., since there the decrease of the fraction of households in working age is more modest after 2030, as we saw in figure 2. During the transition period from 2005-2050, the negative effects of decreasing working age to population ratios therefore dominate the positive effects on output per worker (see the discussion in section 2).

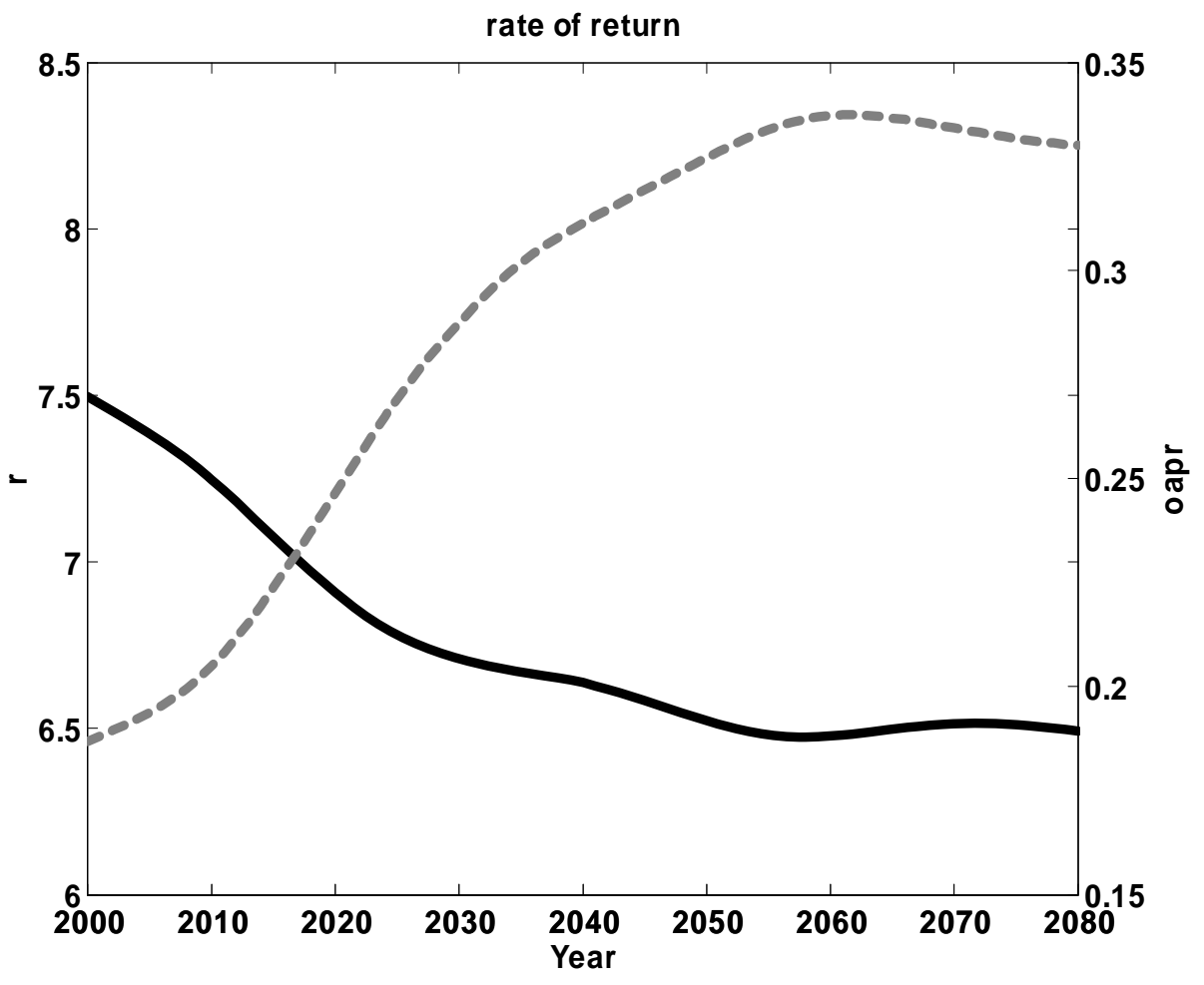

Figure 3: Evolution of World Interest Rates 


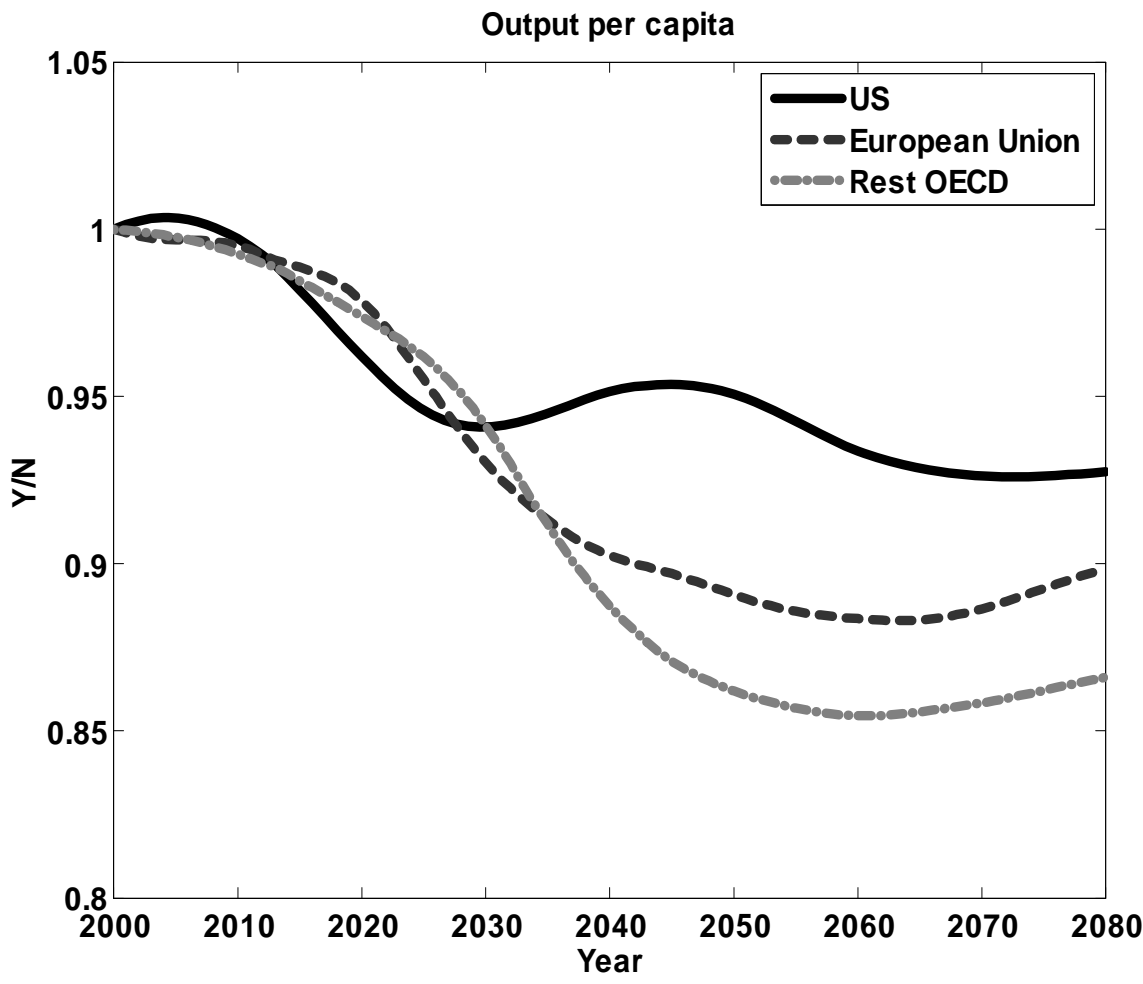

Figure 4: Evolution of GDP per Capita in 3 Regions

\subsection{Quantifying International Capital Flows}

In order to analyze the direction and size of international capital flows we will document the evolution of the net foreign asset position and the current account of the countries/regions under consideration. The current account is given by the change in the net foreign asset position and thus by the difference of country $i^{\prime}$ s saving and investment ${ }^{6}$

$$
\begin{aligned}
C A_{t, i} & =F_{t+1, i}-F_{t, i} \\
& =S_{t, i}-I_{t, i} .
\end{aligned}
$$

When reporting these statistics we always divide them by output $Y_{t, i}$. We start with investigating

${ }^{6}$ Note that in a closed economy $F_{t, i}=C_{t, i}=0$ and that in a balanced growth path of an open economy $C A_{t, i}$ $=g\left(A_{t, i}-K_{t, i}\right)$ Furthermore, net asset positions and current accounts evidently have to sum to 0 across

$$
\sum_{i} F_{t, i}=\sum_{i} C A_{t, i}=0 \text { for all } t
$$

regions: 
national saving and investment rates and then discuss the implied current account and net foreign asset positions.

The most direct effect of an aging population is that labor, as a factor of production, becomes scarce. As a result, for unchanged aggregate saving the return to capital has to fall and gross wages have to rise. This is what we observe in figure 3. However, the decline in interest rates may reduce the incentives of households to save, depending on the relative size of the income and substitution effect. In addition, with the aging of society the age composition of the population shifts towards older households, who are dis-savers in our life cycle model. Consequently savings rates in all regions in our model decline over time. For the next 20 years the fall in savings rates is most pronounced for the U.S., because there, during this time period, the large cohort of baby boomers moves into retirement. The same is true for other regions of the world, albeit to a lesser degree on average ${ }^{7}$. After the large cohort of baby boomers have left the economy (i.e. died) the U.S. saving rate is predicted to rebound (in about 25 to 35 years) and then to stabilize, whereas in the European Union and the rest of the OECD savings rates continue to fall until about 2040 and then stabilize.

The other side of the medal (that is, of the current account) is the investment behavior in the different regions. Given that savings rates decline globally due to population aging investment rates have to do so as well on average, since the world current account has to balance to 0 . As the population ages and the labor force declines it is optimal to reduce the capital stock with which these fewer workers work. Thus investment rates fall.This fall is by far the least pronounced for the U.S.. Furthermore, in the U.S., the investment rate stops to fall by about 2020, roughly a decade earlier than its saving rate. This is due to the fact that the fall in the working age to population ratio is completed around that date in the U.S.. On the other hand, in the EU and the rest of the OECD this ratio continues to fall until 2035. Since capital-(effective) labor ratios have to be equalized, capital allocated to these regions has to fall (relative to the U.S.) and so do

\footnotetext{
${ }^{7}$ Notice that the evolution of demographic variables and the simulated time paths of savings may differ substantially across the countries within each country block, see, e.g., Börsch-Supan, Ludwig and Winter (2006).
} 
investment rates in these regions.

Figure 5 shows the current account to output ratios resulting from these dynamics of saving and investment rates. It depicts a clear deterioration of the U.S. current account of about $2 \%$ of GDP that is expected to occur in the next 30 years, as capital flows from the European Union and, with a slight time delay, from the rest of the OECD, into the U.S.. By 2040 this process is completed and the current account of all countries returns to roughly 0 from that point on. The predicted deterioration in the U.S. current account is due to an investment rate that falls less than in other countries (since the population in the US ages slower and thus the labor force falls less) as well as a (temporary) sharp decline in the U.S. savings rate in the next 20 years due to the gradual retirement of the baby boomers.

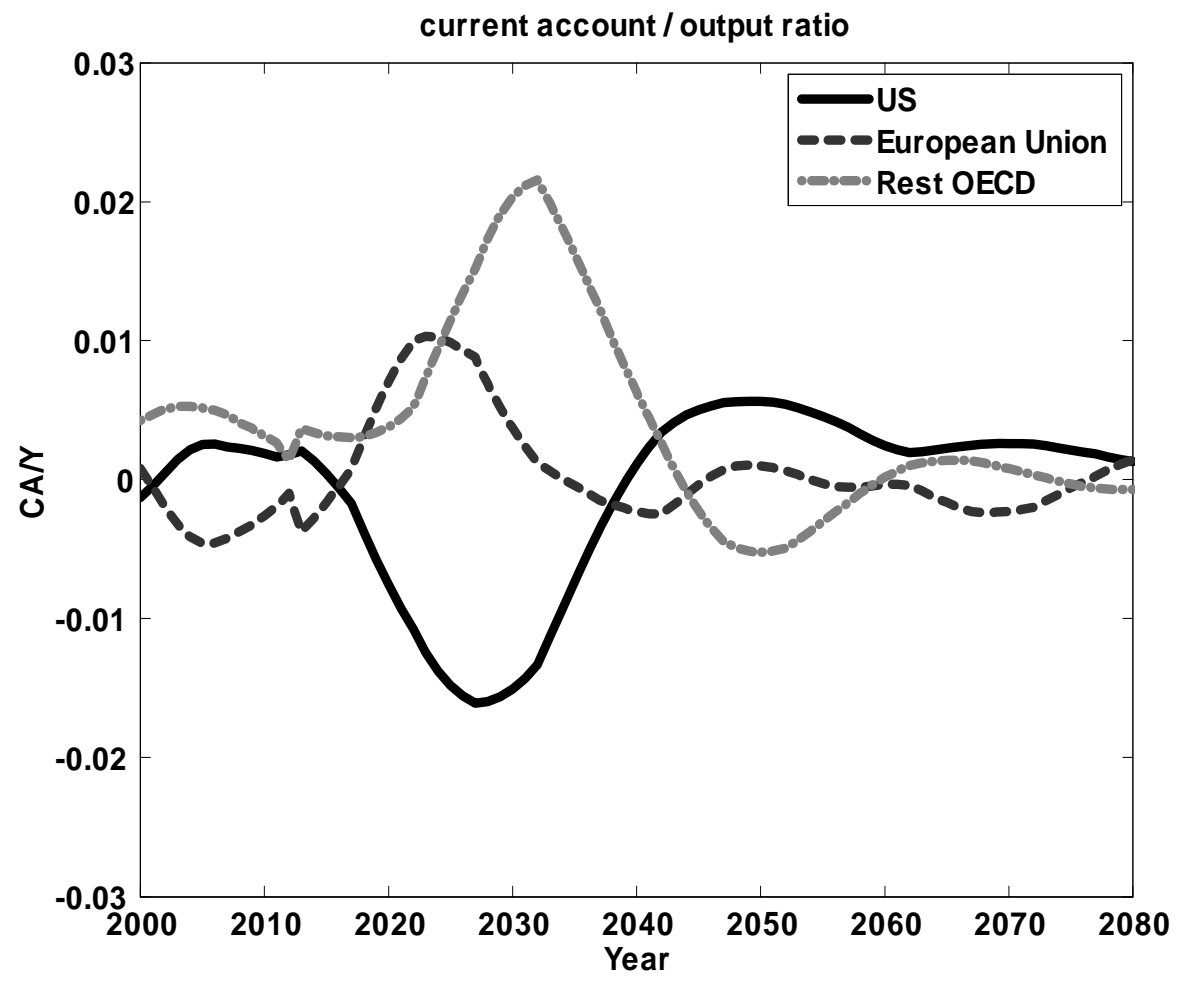

Figure 5: Evolution of the Current Account in 3 Regions

\subsection{Distributional and Welfare Consequences of Demographic Change}

In the previous sections we have documented substantial changes in factor prices induced by the aging of the population, amounting to a decline of about 1 percentage point in real returns to 
capital and an increase in gross wages of about $4 \%$ in the next decades. In this section we want to quantify the distributional and welfare effects emanating from these changes.

\section{Evolution of Inequality}

In figure 6 we display the evolution of income inequality over time in the three regions. Income is composed of labor income (which later will include pension income) and capital income as well as transfers from accidental bequests.

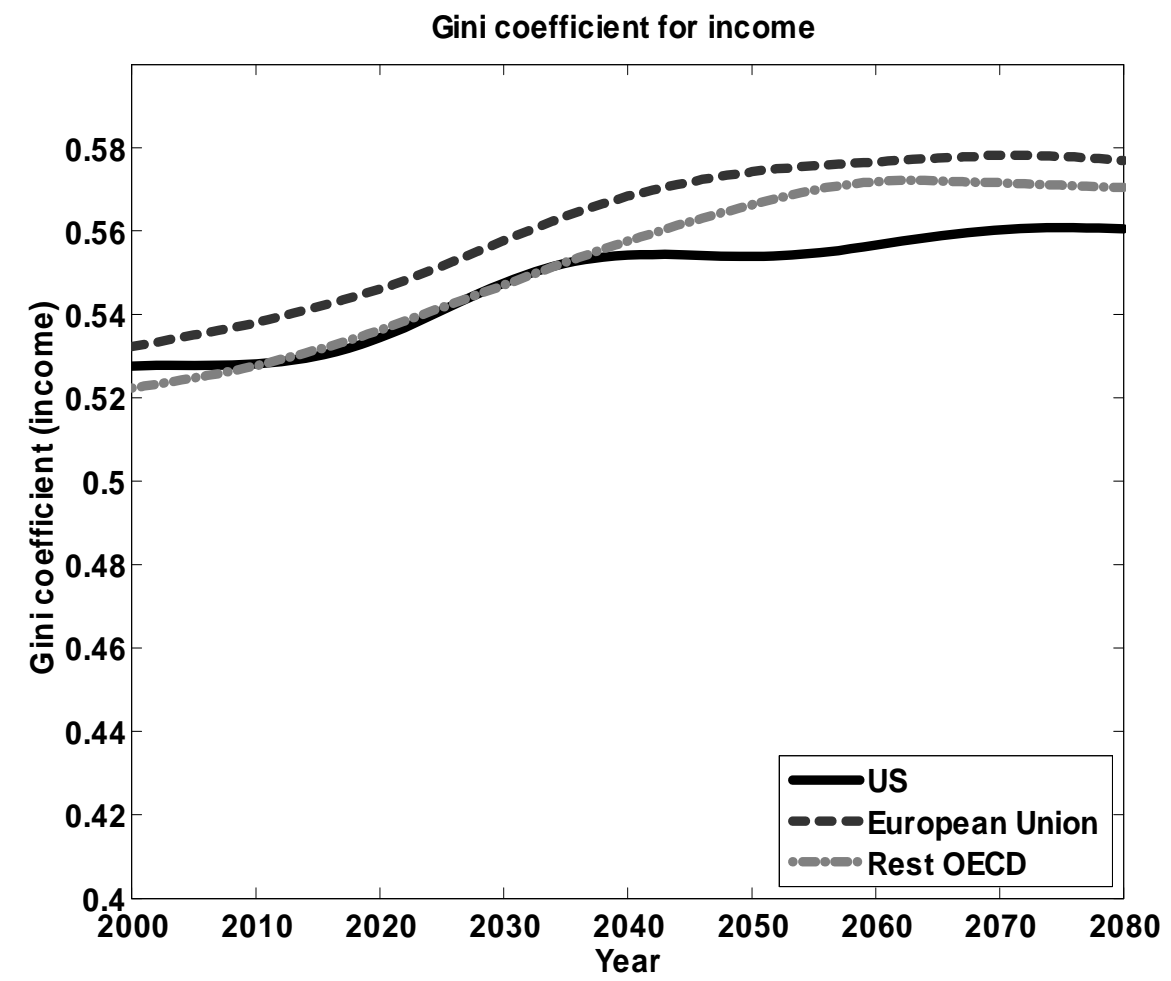

Figure 6: Evolution of Income Inequality in 3 Regions

We observe a significant increase in income inequality between 2000 and 2080, of about 5 points in the Gini coefficient for the EU and the ROECD and 3.5 points in the U.S.. The reason for this increase is mainly a compositional effect. Retired households have significantly lower income on average than households in working age. The demographic transition towards more retired households therefore is bound to increase inequality, especially in those regions where the increase in the fraction of retired households among the population is very pronounced. This explains the more modest increase in income inequality in the U.S.. Note that consumption inequality follows income inequality trends fairly closely in the three regions (and thus is not 
shown here), but increases in consumption inequality are less pronounced. Also notice that the ordering of countries in the figure will be reversed once we add pension systems - then, income will be least equally distributed in the U.S..

The fact that it is not a rise in capital income inequality that drives the increase in total income inequality becomes clear when plotting wealth inequality over time (see Figure 7). There is no discernible increase in the same period; evidently the same is true for capital income inequality since capital income is proportional to wealth.

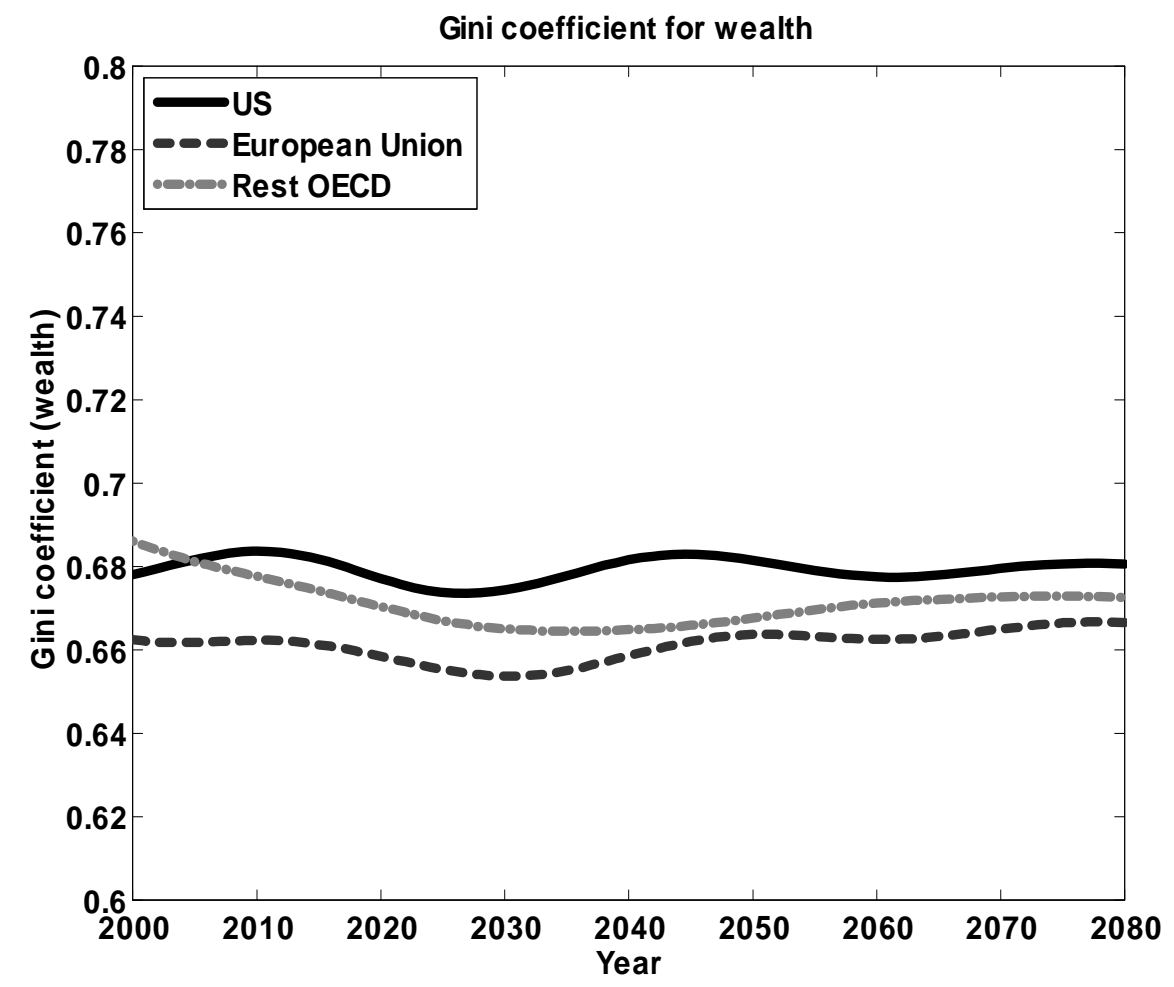

Figure 7: Evolution of Wealth Inequality in 3 Regions

In contrast to income, wealth follows a hump-shaped pattern over the life cycle (on average), with the elderly and the young being wealth-poor. Thus, in contrast to income inequality, the aging of the population does not lead to an increase in wealth inequality, since the demographic change increases the fraction of the elderly, but reduces the fraction of the young. Consequently income and wealth inequality do not follow the same trend over time, nor is the ranking in inequality across regions the same for income and wealth.

We therefore conclude that the opposite general equilibrium effects on wages and interest rates 
have little impact on the income and wealth distribution across generations.

\section{Welfare Consequences of the Demographic Transition}

A household's welfare is affected by two consequences of demographic change. First, her lifetime utility changes because her own survival probabilities increase; this is in part what triggers the aging of the population. Second, due to the demographic transition she faces different factor prices and government transfers and taxes (from the social security system and from accidental bequests) than without changes in the demographic structure. Specifically, households face a path of declining interest rates and increasing wages, relative to the situation without a demographic transition.

We want to isolate the welfare consequences of the second effect. For this we compare lifetime utility of individuals born and already alive in 2005 under two different scenarios. For both scenarios we fix a household's individual survival probabilities at their 2005 values; of course they fully retain their age-dependence. Then we solve each household's problem under two different assumptions about factor prices (and later taxes/transfers, once we have introduced social security). Let $\bar{W}(t, i, j, k, \eta, a)$ denote the lifetime utility of an individual at time $t \geq 2005$ in country $I$ with individual characteristics $(j, k, \eta, a)$ that faces the sequence of equilibrium prices as documented in the previous section, but constant 2005 survival probabilities, and let $\bar{W}_{2005}(t, i, j, k, \eta, a)$ denote the lifetime utility of the same individual that faces prices and taxes/transfers that are held constant at their 2005 value. Finally, denote by $g(t, i, j, k, \eta, a)$ the percentage increase in consumption that needs to be given to an individual $(t, i, j, k, \eta, a)$ at each date and contingency in her remaining lifetime (keeping labor supply allocations fixed) at fixed prices to make her as well off as under the situation with changing prices. ${ }^{8}$ Positive numbers of $g(t, i, j, k, \eta, a)$ thus indicate that households obtain welfare gains from the general equilibrium effects of the demographic changes, negative numbers mean welfare losses. Of particular interest

8For the Cobb-Douglas utility specification for $\sigma \neq 1$ the number $g(t, i, j, k, \eta, a)$ can easily be computed as

$$
g(t, i, j, k, \eta, a)=\left[\frac{\bar{W}(t, i, j, k, \eta, a)}{\bar{W}_{2005}(t, i, j, k, \eta, a)}\right]^{\frac{1}{\omega_{i}(1-\sigma)}} .
$$

A similar expression holds for $\sigma=1$. 
are the numbers $g(t=56, i, j=0, k, \eta, a=0)$ that is, the welfare consequences for newborn individuals in $2005(\mathrm{t}=56)$ (remember that newborns start their life with zero assets).

Table III documents these numbers for type 1 for the U.S., differentiated by their productivity shock $\eta$. The results for type 2 are nearly identical. ${ }^{9}$

Table III: Welfare Cons., US - Pure Demographic Effects

\begin{tabular}{cc}
\hline Productivity $\eta_{1}$ & Productivity $\eta_{2}$ \\
\hline $0.9 \%$ & $0.6 \%$ \\
\hline
\end{tabular}

We make several observations. First, newborn individuals experience welfare gains from changing factor prices and transfers induced by the demographic transition (compare the discussion in section 2). Apart from changing preferences through higher longevity (an effect we control for in our welfare calculations) the demographic transition substantially increases the real wage over time, reduces the interest rate and first increases and then (after 2040) somewhat reduces transfers from accidental bequests. The effect from changes in transfers is small, at least for newborns. The dominating effect for newborn individuals is the substantial increase in wages, partially because these individuals have not yet accumulated assets and thus do not suffer from a loss of capital income on already accumulated financial wealth, in contrast to older households. Of course, a lower interest rate makes it harder for these households to accumulate assets for retirement. Since borrowing is ruled out the decline in interest rates alone therefore has unambiguously negative consequences for welfare.

Second, individuals born with low productivity will experience somewhat higher welfare gains

9The welfare consequences are very similar for other countries and type $k_{2}$. In fact, in the benchmark model the only difference across countries and types stems from accidental bequests, which are redistributed in a lump-sum fashion and whose dynamics varies slightly across countries. Since these transfers are small in magnitude, however, so are the cross-country and cross-type differences in welfare. 
than individuals that start their working life with high productivity. Low productivity individuals expect higher productivity in the future, and thus benefit more strongly from the increasing wage profile induced by the demographic transition than the currently highly productive, whose productivity is going to fall in expectation.

Given that the welfare impact of changing factor prices constitutes a trade-off between increasing wages and falling returns to capital one would expect that those members of society for whom labor income constitutes a smaller part of (future) resources than capital income benefit less from the demographic transition. An advantage of our model with uninsurable idiosyncratic income shocks and thus endogenous intra-cohort wealth heterogeneity is that it allows us to document how the welfare consequences are distributed across the population, both across and within cohorts. Figure 8 plots the welfare gains for individuals of age 60 in 2005 . These households

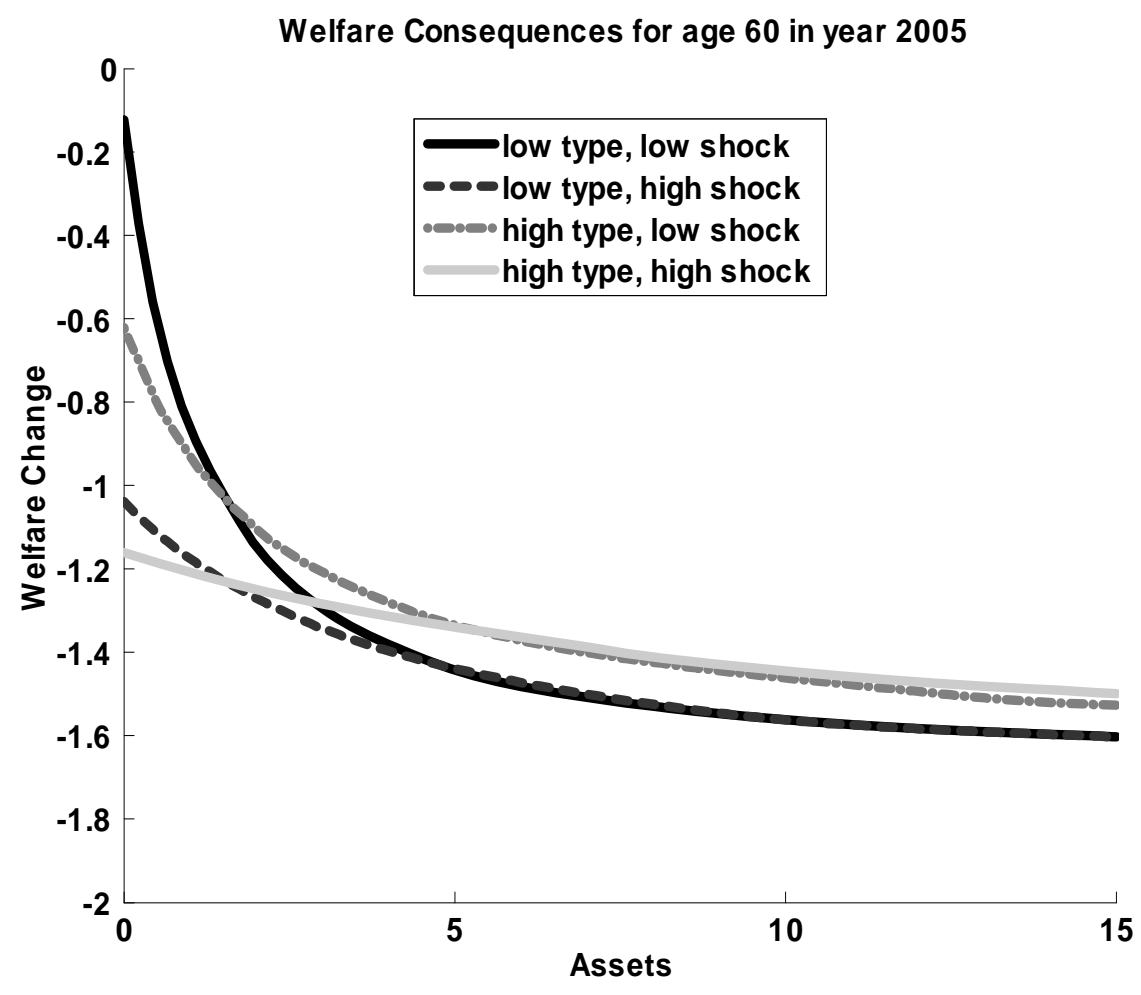

Figure 8: Welfare Change

have most of their working life behind them, thus are fairly unaffected by the wage changes, and simply experience lower returns on their accumulated savings. We see that individuals in this cohort suffer welfare losses which increase substantially by the amount of financial assets they 
have already accumulated. To give a sense of how many individuals there are at different points in the asset distribution, the support of this distribution for the 60 year old ranges roughly to $a=$ 12 (about 19 times GDP per capita), with median asset levels around 4 (10) times GDP per capita for the low $\eta$-low (high) type individuals and about 4.1 (10.8) times GDP per capita for the high n-low (high) type individuals. Overall, a fraction of 38 percent of individuals economically alive in 2005 gain from the changing factor prices. These tend to be young individuals with little assets and currently low labor productivity.

\subsection{The Role of Social Security}

So far, we have abstracted from government policies. An idealized pay as you go public pension system can respond to an increase in the share of pensioners in the population by (a combination of) at least three ways: cutting benefits, increasing social security contribution rates or increasing the retirement age. While a likely response will include all elements, we now present results for the model with a PAYGO social security system that responds to population aging by either holding tax rates fixed (and thus cutting benefits), by holding replacement rates fixed (and thus raising taxes), or by increasing the retirement age. ${ }^{10}$

Because of the strong influence of a public pension system on private savings behavior, we expect that these different reform scenarios may have substantially different implications for the evolution of factor prices and the size and direction of international capital flows as well as the distribution of welfare. This conjecture turns out to be correct. Note that for all exercises we recalibrate production and preference parameters such that each economy (with the different social security systems) attains the same calibration targets for the 1950 to 2004 period.

In table $\mathrm{V}$ we show how the evolution of macroeconomic aggregates and prices differs across the various scenarios for social security. Comparing the no-social security scenario to a world with social security in which payroll tax rates are held constant (and thus benefits decline), we observe that changes in factor prices are roughly the same between the two scenarios. ${ }^{11}$ One big

10In our experiment we increase the mandatory retirement age by 5 years in 2005, and keep contribution rates fixed. When needed, benefits are adjusted to retain budget balance of the social security system.

${ }^{11}$ Remember that we recalibrate our model so that in all scenarios the pre-2005 equilibrium features the 
difference, however, is the change in social security benefits required to cope with the demographic transition, which implies a decline in replacement rates by about 5 percentage points in the scenario with social security. Column 4 demonstrates that keeping pension benefits constant and adjusting taxes, on the other hand, has dramatic consequences for the evolution of interest rates

Table IV. Evolution of Aggregates in US, 2005-2050

\begin{tabular}{lcccc}
\hline Var. & No Soc.Sec. & $\tau$ fixed & $\rho$ fixed & Adj of $j r$ \\
\hline$r$ & $-0.86 \%$ & $-0.82 \%$ & $-0.26 \%$ & $-0.79 \%$ \\
$w$ & $4.1 \%$ & $3.8 \%$ & $1.2 \%$ & $3.6 \%$ \\
$T$ & $0 \%$ & $0 \%$ & $5.9 \%$ & $0 \%$ \\
$P$ & $0 \%$ & $-7.0 \%$ & $0 \%$ & $-10.0 \%$ \\
$Y / N$ & $-5.2 \%$ & $-5.2 \%$ & $-9.5 \%$ & $-3.8 \%$ \\
$C / N$ & $-4.7 \%$ & $-4.7 \%$ & $-7.4 \%$ & $-2.6 \%$ \\
\hline \hline
\end{tabular}

and wages, relative to the benchmark scenario of fixing tax rates for social security. With fixed benefits the incentives to save for retirement are drastically reduced, relative to the benchmark. In addition, the substantial increase in tax rates of 6 percentage points and the corresponding reduction in after tax wages make it harder to save. Therefore, despite the decline in the fraction of households in working age (and diminished incentives to work because of higher payroll taxes) now the capital-labor ratio remains roughly unchanged, because of the large reduction of household savings. Consequently the increase in wages and decline in returns is much less pronounced in this scenario. Finally, the last column of table IV shows that an increase in the 
retirement age by 5 years, while leaving the change in factor prices roughly the same as in the benchmark, implies a much smaller decline in benefits as with a retirement age of 65 (see column 2). ${ }^{12}$ Because of the expansion in labor supply output per capita falls significantly less in this scenario than in all others.

Given these substantial differences in changes of allocations it is not surprising that the welfare consequences differ across these two scenarios as well. Table V summarizes the welfare losses from the demographic transition for newborns in the U.S. in $2005 .{ }^{13}$ We find that, because of the decline in benefits or the increase in taxes, the welfare implications from the demographic change are less favorable in a world with social security than without. Especially the policy option of keeping benefits constant and letting tax rates increase implies large welfare losses from population aging for newborns, and even more so for future generations (not shown here). If, in contrast, the retirement age is increased to age 70, low-type households who enter the labor market unproductive are especially benefiting. These households expect productivity to be higher in the future, face increasing wages and can exploit these longer now as they can work until age 70. It is therefore this group for which the increase in wages presents a good opportunity to intertemporally substitute labor supply; consequently the benefit of being able to work longer and thus the overall welfare gains from changing factor prices are largest for this group. For older individuals the welfare losses from the demographic transition are significantly smaller with an expansion of the retirement age, relative to simply holding contribution rates fixed and let benefits decline (results not shown). Older households are given the option to endogenously respond to lower benefit levels by expanding their labor supply for five more years.

\footnotetext{
${ }^{12} \mathrm{~A}$ further increase in the retirement age has no substantial effect on labor supply since households are not very productive beyond age 70 and thus choose to voluntarily retire around that age.

${ }^{13}$ Note that the numbers of table VI do permit a meaningful welfare comparison of different social security reform scenarios to deal with the demographic change. In order to achieve this comparability in our welfare computations (and in these only) we always use the same parameters for all scenarios, those calibrated for the no social security benchmark.
}

The table does not, however, permit an assessment as to whether households are better off in a world with or without social security. 
Thus we conclude that the option of increasing the retirement age leads to less welfare losses (and even welfare gains for some groups) from population aging than adjusting taxes or benefits alone.

Table V. Welfare Consequences, Newborns in U.S.

\begin{tabular}{|c|c|c|c|c|c|c|c|c|}
\hline \multirow[b]{2}{*}{ Type } & \multicolumn{2}{|c|}{ No Soc.Sec. } & \multicolumn{2}{|c|}{$\tau$ fixed } & \multicolumn{2}{|c|}{$\rho$ fixed } & \multicolumn{2}{|c|}{ Adj of $j r$} \\
\hline & $\eta_{1}$ & $\eta_{2}$ & $\eta_{1}$ & $\eta_{2}$ & $\eta_{1}$ & $\mathrm{H}_{2}$ & $\eta_{1}$ & $\eta_{2}$ \\
\hline$K_{l}$ & $0.9 \%$ & $0.6 \%$ & $0.8 \%$ & $0.2 \%$ & $-1.6 \%$ & $-1.8 \%$ & $1.4 \%$ & $0.6 \%$ \\
\hline$K_{2}$ & $0.9 \%$ & $0.6 \%$ & $0.4 \%$ & $0.0 \%$ & $-1.8 \%$ & $-1.9 \%$ & $0.8 \%$ & $0.3 \%$ \\
\hline
\end{tabular}

\subsection{The Role of Idiosyncratic Risk}

We now investigate the role of idiosyncratic risk and ask whether our quantitative predictions change when we ignore idiosyncratic risk as has been done in earlier analyses (e.g., BörschSupan, Ludwig and Winter, 2006). In order to illustrate the interactions between relative price changes and the insurance role of the pension system we here take as a benchmark scenario a social security system with fixed contribution rates. We then recalibrate the model such as to meet the same calibration targets on the aggregate level. Since a precautionary savings motive is not at work in an economy without risk, we have to increase the discount factor by two percentage points to make households sufficiently impatient such as to meet the calibration target of the capital output ratio. Our results for macroeconomic aggregates are summarized in table VI. Relative price changes are stronger in the scenario with risk because hours worked decrease more strongly and therefore social security benefits are more strongly reduced. As a consequence of the interplay of both effects, the capital output ratio increases by more and therefore the relative price effects are slightly stronger than in the scenario without risk.

Finally, Table VII compares the welfare consequences of demographic change across the two scenarios. In these welfare comparisons we isolate the role of idiosyncratic risk by holding preference parameters constant (as before in table V) and by evaluating the welfare consequences for the equilibrium prices that resulted from our pure $\tau$ fixed scenario. With the exception of low 
type, low shock households, all households are better off in a world without risk. By the mean reverting pattern of our wage processes, uncertainty about future wage income represents a chance for low type, low shock households.

Table VI. US Aggregates, 2005-80 - The Role of Risk

\begin{tabular}{lcc}
\hline Var. & $\tau$ fixed & $\tau$ fixed - no risk \\
\hline$r$ & $-0.82 \%$ & $-0.75 \%$ \\
$w$ & $3.8 \%$ & $3.5 \%$ \\
$\tau$ & $0 \%$ & $0 \%$ \\
$\rho$ & $-7.0 \%$ & $-6.3 \%$ \\
$Y / N$ & $-5.2 \%$ & $-3.9 \%$ \\
$C / N$ & $-4.7 \%$ & $-3.0 \%$ \\
\hline \hline
\end{tabular}

Table VII: Welfare Consequences - The Role of Risk

\begin{tabular}{|c|c|c|c|}
\hline & \multicolumn{2}{|c|}{$\tau$ fixed } & \multirow[t]{2}{*}{$\tau$ fixed - no risk } \\
\hline Type & $\eta_{1}$ & $\eta_{2}$ & \\
\hline$K_{1}$ & $0.8 \%$ & $0.2 \%$ & $0.7 \%$ \\
\hline$K_{2}$ & $0.4 \%$ & $0.0 \%$ & $0.5 \%$ \\
\hline
\end{tabular}




\section{Conclusions}

In all major industrialized countries the population is aging, bringing with it a potentially large impact on the returns to the production factors capital and labor. This paper reports that the rate of return to capital can be expected to decrease by about 80 to 90 basis points until 2050 with a corresponding increase of wages if PAYG social security systems are reformed such that contribution rates are held constant. Under such a reform, the welfare consequences from population aging through increasing wages and declining rates of return are positive in the order of up to $1 \%$ in lifetime consumption for newborns in 2005 . This number masks important distributional shifts: households that have already accumulated assets lose from the decline in rates of return. As an interesting policy effect, our paper also shows that increasing the mandatory retirement age by five years is shown to substantially mitigate these losses and to significantly increase welfare gains of newborns.

The welfare gains for newborns are actually larger than what we compute since in addition these newborns are expected to live longer than the current generation. Similarly, the welfare losses for older asset holders are smaller, since they also have a longer life expectancy. Quantifying the utility gains from living longer is beyond the scope of this paper.

Future research will be devoted to several valuable additions. One important channel of adjustment to a shrinking labor force that we have abstracted from is endogenous human capital accumulation. Higher returns to human capital in the form of higher wages may make it optimal for young (and possibly older) households to obtain a better education, increasing the supply of effective labor. This effect may counteract some of the increase in the capital-labor ratio and hence mitigate the impact of population aging on factor prices. Another addition will be to differentiate among asset types. For example, out of life-cycle investment motives one may expect a stronger decrease of the rate of return on risk free assets and thus an increase of the equity premium. These issues are left for future research. 


\section{References}

Abel, A. (2003), The Effects of a Baby Boom on Stock Prices and Capital Accumulation in the Presence of Social Security, Econometrica, 71, 551-578.

Altig, D., A. Auerbach, L. Kotlikoff, K. Smetters and J. Walliser (2001), Simulating Fundamental Tax Reform in the U.S., American Economic Review, 91, 574-595.

Attanasio, O., S. Kitao and G. Violante (2006a), Quantifying the Effects of the Demographic Transition in Developing Economies, Advances in Macroeconomics, 2, Article 2.

Attanasio, O., S. Kitao and G. Violante (2006b), Global Demographic Trends and Social Security Reform, forthcoming, Journal of Monetary Economics.

Auerbach, A. and L. Kotlikoff (1987), Dynamic Fiscal Policy, Cambridge University Press, Cambridge.

Bloom, D. and J. Williamson (1998), Demographic Transitions and Economic Miracles in Emerging Asia, World Bank Economic Review, 12(3), 419-455.

Börsch-Supan, A. (1996): The impact of population aging on savings, investment and growth in the OECD area. In: Future Global Capital Shortages: Real Threat or Pure Fiction? Paris: OECD, 103-141.

Börsch-Supan, A., A. Ludwig, and J. Winter (2002): Aging and international capital flows. In: A. Auerbach and H. Hermann (eds.), Aging, Financial Markets and Monetary Policy. Heidelberg: Springer, 55-83.

Börsch-Supan, A, A. Ludwig and J. Winter (2006), Aging, Pension Reform, and Capital Flows: A Multi-Country Simulation Model, Economica, 73, 625-658.

Brooks, R. (2003), Population Aging and Global Capital Flows in a Parallel Universe, IMF Staff Papers, 50, 200-221.

Conesa, J. and D. Krueger (1999), Social Security Reform with Heterogeneous Agents, Review of Economic Dynamics, 2, 757-795.

Conesa, J. and D. Krueger (2005), On the Optimal Progressivity of the Income Tax Code, forthcoming, Journal of Monetary Economics.

De Nardi, M., S. İmrohoroğlu and T. Sargent (1999), Projected U.S. demographics and Social 
Security, Review of Economic Dynamics, 2, 575-615.

Domeij, D. and M. Floden (2005), Population Aging and International Capital Flows, forthcoming, International Economic Review.

Fehr, H., S. Jokisch and L. Kotlikoff (2005), The Developed World's demographic Transition The Role of Capital Flows, Immigration and Policy, in R. Brooks and A. Razin (eds.) Social Security Reform - Financial and Political Issues in International Perspective, Cambridge University Press, Cambridge.

Feroli, M. (2003), Capital Flows Among the G-7 Nations: A Demographic Perspective, Finance and Economics Discussion Series 2003-54, Washington: Board of Governors of the Federal Reserve System, 2003.

Henriksen, E. (2002), A Demographic Explanation of U.S. and Japanese Current Account Behavior, mimeo, Carnegie Mellon University.

Huang, H., S. İmrohoroğlu and T. Sargent (1997), Two Computations to Fund Social Security, Macroeconomic Dynamics, 1, 7-44.

İmrohoroğlu, A., S. İmrohoroğlu and D. Joines (1995), A Life Cycle Analysis of Social Security, Economic Theory, 6, 83-114.

İmrohoroğlu, A., S. İmrohoroğlu and D. Joines (1995), Social Security in an Overlapping Generations Economy with Land, Review of Economic Dynamics, 2, 638-665.

Krüger, D. and A. Ludwig (2006), On the Consequences of Demographic Change for Rates of Returns to Capital, and the Distribution of Wealth and Welfare, forthcoming, Journal of Monetary Economics.

Ludwig, A. (2005), Moment Estimation in Auerbach-Kotlikoff Models: How Well Do They Match the Data?, mimeo, MEA, University of Mannheim.

Ludwig, A. (2006), The Gauss-Seidel-Quasi-Newton Method: A Hybrid Algorithm for Solving Dynamic Economic Models, forthcoming, Journal of Economic Dynamics and Control.

Nataraj, S., und J. B. Shoven (2003), Comparing the Risks of Social Security with and without Individual Accounts, American Economic Review, Papers and Proceedings, 92, 348-353.

Obstfeld, M. and K. Rogoff (1995), The Intertemporal Approach to the Current Account, in G. 
Grossman and K. Rogoff (eds.) Handbook of International Economics, Vol. 3, Elsevier, Amsterdam.

United Nations (2002), World Population Prospects: The 2002 Revision, United Nations Population Division, United Nations, New York. 